\title{
The theory contribution of case study research designs
}

\author{
Hans-Gerd Ridder ${ }^{1}$
}

Received: 26 January 2016/ Accepted: 6 February 2017/Published online: 16 February 2017

(c) The Author(s) 2017. This article is published with open access at Springerlink.com

\begin{abstract}
The objective of this paper is to highlight similarities and differences across various case study designs and to analyze their respective contributions to theory. Although different designs reveal some common underlying characteristics, a comparison of such case study research designs demonstrates that case study research incorporates different scientific goals and collection and analysis of data. This paper relates this comparison to a more general debate of how different research designs contribute to a theory continuum. The fine-grained analysis demonstrates that case study designs fit differently to the pathway of the theory continuum. The resulting contribution is a portfolio of case study research designs. This portfolio demonstrates the heterogeneous contributions of case study designs. Based on this portfolio, theoretical contributions of case study designs can be better evaluated in terms of understanding, theory-building, theory development, and theory testing.
\end{abstract}

Keywords Case studies - Research design - Heterogeneity of case study designs · Theory continuum · Methodological fit · Contribution to theory

I thank two anonymous reviewers for their constructive comments. I am grateful for valuable thoughts generously provided by Ann Kristin Zobel.

Hans-Gerd Ridder

ridder@pua.uni-hannover.de

1 Institute of Human Resource Management, Leibniz University of Hannover, Königsworther Platz 1, 30167 Hannover, Germany 


\section{Introduction}

Case study research scientifically investigates into a real-life phenomenon in-depth and within its environmental context. Such a case can be an individual, a group, an organization, an event, a problem, or an anomaly (Burawoy 2009; Stake 2005; Yin 2014). Unlike in experiments, the contextual conditions are not delineated and/or controlled, but part of the investigation. Typical for case study research is nonrandom sampling; there is no sample that represents a larger population. Contrary to quantitative logic, the case is chosen, because the case is of interest (Stake 2005), or it is chosen for theoretical reasons (Eisenhardt and Graebner 2007). For within-case and across-case analyses, the emphasis in data collection is on interviews, archives, and (participant) observation (Flick 2009: 257; Mason 2002: 84). Case study researchers usually triangulate data as part of their data collection strategy, resulting in a detailed case description (Burns 2000; Dooley 2002; Eisenhardt 1989; Ridder 2016; Stake 2005: 454). Potential advantages of a single case study are seen in the detailed description and analysis to gain a better understanding of "how" and "why" things happen. In single case study research, the opportunity to open a black box arises by looking at deeper causes of the phenomenon (Fiss 2009). The case data can lead to the identification of patterns and relationships, creating, extending, or testing a theory (Gomm et al. 2000). Potential advantages of multiple case study research are seen in cross-case analysis. A systematic comparison in cross-case analysis reveals similarities and differences and how they affect findings. Each case is analyzed as a single case on its own to compare the mechanisms identified, leading to theoretical conclusions (Vaughan 1992: 178). As a result, case study research has different objectives in terms of contributing to theory. On the one hand, case study research has its strength in creating theory by expanding constructs and relationships within distinct settings (e.g., in single case studies). On the other hand, case study research is a means of advancing theories by comparing similarities and differences among cases (e.g., in multiple case studies).

Unfortunately, such diverging objectives are often neglected in case study research. Burns (2000: 459) emphasizes: "The case study has unfortunately been used as a 'catch -all' category for anything that does not fit into experimental, survey, or historical methods."

Therefore, this paper compares case study research designs. Such comparisons have been conducted previously regarding their philosophical assumptions and orientations, key elements of case study research, their range of application, and the lacks of methodological procedures in publications. (Baxter and Jack 2008; Dooley 2002; Dyer and Wilkins 1991; Piekkari et al. 2009; Welch et al. 2011). This paper aims to compare case study research designs regarding their contributions to theory.

Case study research designs will be analyzed regarding their various strengths on a theory continuum. Edmondson and McManus (2007) initiated a debate on whether the stage of theory fits to research questions, style of data collection, and analyses. Similarly, Colquitt and Zapata-Phelan (2007) created a taxonomy capturing facets of empirical article's theoretical contributions by distinguishing between theorybuilding and theory testing. Corley and Gioia (2011) extended this debate by 
focusing on the practicality of theory and the importance of prescience. While these papers consider the whole range of methodological approaches on a higher level, they treat case studies as relatively homogeneous. This paper aims to delve into a deeper level of analysis by solely focusing on case study research designs and their respective fit on this theory continuum. This approach offers a more fine-grained understanding that sheds light on the diversity of case study research designs in terms of their differential theory contributions. Such a deep level of analysis on case study research designs enables more rigor in theory contribution. To analyze alternative case study research designs regarding their contributions to theory, I engage into the following steps:

First, differences between case study research designs are depicted. I outline and compare the case study research designs with regard to the key elements, esp. differences in research questions, frameworks, sampling, data collection, and data analysis. These differences result in a portfolio of various case study research designs.

Second, I outline and substantiate a theory continuum that varies between theorybuilding, theory development, and testing theory. Based on this continuum, I analyze and discuss each of the case study research designs with regard to their location on the theory continuum. This analysis is based on a detailed differentiation of the phenomenon (inside or outside the theory), the status of the theory, research strategy, and methods.

As a result, the contribution to the literature is a portfolio of case study research designs explicating their unique contributions to theory. The contribution of this paper lies in a fine-grained analysis of the interplay of methods and theory (van Maanen et al. 2007) and the methodological fit (Edmondson and McManus 2007) of case study designs and the continuum of theory. It demonstrates that different designs have various strengths and that there is a fit between case study designs and different points on a theory continuum. If there is no clarity as to whether a case study design aims at creating, elaborating, extending, or testing theory, the contribution to theory is difficult to identify for authors, reviewers, and readers. Consequently, this paper aims to clarify at which point of the continuum of theory case study research designs can provide distinct contributions that can be identified beyond their traditionally claimed exploratory character.

\section{Differences across case study design: a portfolio approach}

Only few papers have compared case study research designs so far. In all of these comparisons, the number of designs differs as well as the issues under consideration. In an early debate between Dyer and Wilkins (1991) and Eisenhardt (1991), Dyer and Wilkins compared the case study research design by Eisenhardt (1989) with "classical" case studies. The core of the debate concerns a difference between in-depth single case studies (classical case study) to a focus on the comparison of multiple cases. Dyer and Wilkins (1991: 614) claim that the essence of a case study lies in the careful study of a single case to identify new relationships and, as a result, question the Eisenhardt approach which puts a lot of emphasis on comparison of 
multiple cases. Eisenhardt, on the contrary, claims that multiple cases allow replication between cases and is, therefore, seen as a means of corroboration of propositions (Eisenhardt 1991). Classical case studies prefer deep descriptions of a single case, considering the context to reveal insights into the single case and by that elaborate new theories. The comparison of multiple cases, therefore, tends-in the opinion of Dyer and Wilkens - to surface descriptions. This weakens the possibility of context-related, rich descriptions. While, in classic case study, good stories are the aim, the development of good constructs and their relationships is aimed in Eisenhardt's approach. Eisenhardt (1991: 627) makes a strong plea on more methodological rigor in case study research, while Dyer and Wilkins (1991: 613) criticize that the new approach "... includes many of the attributes of hypothesistesting research (e.g., sampling and controls)."

Dooley (2002: 346) briefly takes the case study research designs by Yin (1994) and Eisenhardt (1989) as exemplars of how the processes of case study research can be applied. The approach by Eisenhardt is seen as an exemplar that advances conceptualization and operationalization in the phases of theory-building, while the approach by Yin is seen as exemplar that advances minimally conceptualized and operationalized existing theory.

Baxter and Jack (2008) describe the designs by Yin (2003) and Stake (1995) to demonstrate key elements of qualitative case study. The authors outline and carefully compare the approaches by Yin and Stake in conducting the research process, neglecting philosophical differences and theoretical goals.

Piekkari et al. (2009) outline the methodological richness of case study research using the approaches of Yin et al. (1998), and Stake. They specifically exhibit the role of philosophical assumptions, establishing differences in conventionally accepted practices of case study research in published papers. The authors analyze 135 published case studies in four international business journals. The analysis reveals that, in contrast to the richness of case study approaches, the majority of published case studies draw on positivistic foundations and are narrowly declared as explorative with a lack of clarity of the theoretical purpose of the case study. Case studies are often designed as multiple case studies with cross-sectional designs based on interviews. In addition to the narrow use of case study research, the authors find out that "... most commonly cited methodological literature is not consistently followed" (Piekkari et al. 2009: 567).

Welch et al. (2011) develop a typology of theorizing modes in case study methods. Based on the two dimensions "contextualization" and "causal explanation", they differentiate in their typology between inductive theory-building (Eisenhardt), interpretive sensemaking (Stake), natural experiment (Yin), and contextualised explanation (Ragin/Bhaskar). The typology is used to analyze 199 case studies from three highly ranked journals over a 10-year period for whether the theorizing modes are exercised in the practice of publishing case studies. As a result, the authors identify a strong emphasis on the exploratory function of case studies, neglecting the richness of case study methods to challenge, refine, verify, and test theories (Welch et al. 2011: 755). In addition, case study methods are not consistently related to theory contribution: "By scrutinising the linguistic elements of texts, we found that case researchers were not always clear and consistent in the 
way that they wrote up their theorising purpose and process" (Welch et al. 2011: 756).

As a result, the comparisons reveal a range of case study designs which are rarely discussed. In contrast, published case studies are mainly introduced as exploratory design. Explanatory, interpretivist, and critical/reflexive designs are widely neglected, narrowing the possible applications of case study research. In addition, comparisons containing an analysis of published case studies reveal a low degree in accuracy when applying case study methods.

What is missing is a comparison of case study research designs with regard to differences in the contribution to theory. Case study designs have different purposes in theory contribution. Confusing these potential contributions by inconsistently utilizing the appropriate methods weakens the contribution of case studies to scientific progress and, by that, damages the reputation of case studies.

To conduct such a comparison, I consider the four case study research approaches of Yin, Eisenhardt, Burawoy, and Stake for the following reasons.

These approaches are the main representatives of case study research design outlined in the comparisons elaborated above (Baxter and Jack 2008; Dooley 2002; Dyer and Wilkins 1991; Piekkari et al. 2009; Welch et al. 2011). I follow especially the argument by Piekkari et al. (2009) that these approaches contain a broad spectrum of methodological foundations of exploratory, explanatory, interpretivist, and critical/reflexive designs. The chosen approaches have an explicit and detailed methodology which can be reconstructed and compared with regard to their theory contribution. Although there are variations in the application of the designs, to the best of my knowledge, the designs represent the spectrum of case study methodologies. A comparison of these methodologies revealed main distinguishable differences. To highlight these main differences, I summarized these differences into labels of "no theory first"; "gaps and holes"; "social construction of reality"; and "anomalies".

I did not consider descriptions of case study research in text books which focus more or less on general descriptions of the common characteristics of case studies, but do not emphasize differences in methodologies and theory contribution. In addition, I did not consider so-called "home grown" designs (Eisenhardt 1989: 534) which lack a systematic and explicit demonstration of the methodology and where "... the hermeneutic process of inference-how all these interviews, archival records, and notes were assembled into a coherent whole, what was counted and what was discounted-remains usually hidden from the reader" (Fiss 2009: 425).

Finally, although often cited in the methodological section of case studies, books are not considered which concentrate on data analysis in qualitative research per se (Miles et al. 2014; Corbin and Strauss 2015). Therefore, to analyze the contribution of case study research to the scientific development, it needs to compare explicit methodology. This comparison will be outlined in the following sections with regard to main methodological steps: the role of the case, the collection of data, and the analysis of data. 


\subsection{Case study research design 1: no theory first}

A popular template for building theory from case studies is a paper by Eisenhardt (1989). It follows a dramaturgy with a precise order of single steps for constructing a case study and is one of the most cited papers in methods sections (Ravenswood 2011). This is impressive for two reasons. On the one hand, Eisenhardt herself has provided a broader spectrum of case study research designs in her own empirical papers, for example, by combining theory-building and theory elaboration (Bingham and Eisenhardt 2011). On the other hand, she "updated" her design in a paper with Graebner (Eisenhardt and Graebner 2007), particularly by extending the range of inductive theory-building. These developments do not seem to be seriously considered by most authors, as differences and elaborations of this spectrum are rarely found in publications. Therefore, in the following, I focus on the standards provided by Eisenhardt (1989) and Eisenhardt and Graebner (2007) as exemplary guidelines.

Eisenhardt follows the ideal of 'no theory first' to capture the richness of observations without being limited by a theory. The research question may stem from a research gap meaning that the research question is of relevance. Tentative a priori constructs or variables guide the investigation, but no relationships between such constructs or variables are assumed so far: "Thus, investigators should formulate a research problem and possibly specify some potentially important variables, with some reference to extant literature. However, they should avoid thinking about specific relationships between variables and theories as much as possible, especially at the outset of the process" (Eisenhardt 1989: 536).

Cases are chosen for theoretical reasons: for the likelihood that the cases offer insights into the phenomenon of interest. Theoretical sampling is deemed appropriate for illuminating and extending constructs and identifying relationships for the phenomenon under investigation (Eisenhardt and Graebner 2007). Cases are sampled if they provide an unusual phenomenon, replicate findings from other cases, use contrary replication, and eliminate alternative explanations.

With respect to data collection, qualitative data are the primary choice. Data collection is based on triangulation, where interviews, documents, and observations are often combined. A combination of qualitative data and quantitative data is possible as well (Eisenhardt 1989: 538). Data analysis is conducted via the search for within-case patterns and cross-case patterns. Systematic procedures are conducted to compare the emerging constructs and relationships with the data, eventually leading to new theory.

A good exemplar for this design is the investigation of technology collaborations (Davis and Eisenhardt 2011). The purpose of this paper is to understand processes by which technology collaborations support innovations. Eight technology collaborations among ten firms were sampled for theoretical reasons. Qualitative and quantitative data were used from semi-structured interviews, public and private data, materials provided by informants, corporate intranets, and business publications. The data was measured, coded, and triangulated. Writing case histories was a basis for within-case and cross-case analysis. Iteration between cases and emerging 
theory and considering the relevant literature provided the basis for the development of a theoretical framework.

Another example is the investigation of what is learned in organizational processes (Bingham and Eisenhardt 2011). This paper demonstrates that the case study design is not only used for theory-building, but can also be combined with theory elaboration. Based on the lenses of the organizational knowledge literature, organizational routines literature, and heuristics literature, six technology-based ventures were chosen for theoretical reasons. Several data sources were used, especially quantitative and qualitative data from semi-structured interviews, archival data, observations, e-mails, phone calls, and follow-up interviews. Within-case analysis revealed what each firm has learned from process experience. Cross-case analysis revealed emerging patterns from which tentative constructs and propositions were formed. In replication logic constructs and propositions were refined across the cases. When mirroring the findings with the literature, both the emergences of the constructs were compared and unexpected types were considered. The iteration of theory and data as well as the consideration of related research sharpened the theoretical arguments, eventually leading to a theoretical framework. "Thus, we combined theory elaboration (Lee 1999) and theory generation (Eisenhardt 1989)" (Bingham and Eisenhardt 2011: 1448).

\subsection{Case study research design 2: gaps and holes}

Contrary to "No Theory First", case study research design can also aim at specifying gaps or holes in existing theory with the ultimate goal of advancing theoretical explanations (Ridder 2016). A well-known template for this case study research design is the book by Yin (2014). It is a method-orientated handbook of how to design single and multiple case studies with regard to this purpose. Such a case study research design includes: "A 'how' and 'why' question" (Yin 2014: 14). Research questions can be identified and shaped using literature to narrow the interest in a specific topic, looking for key studies and identifying questions in these studies. According to Yin's design, existing theory is the starting point of case study research. In addition, propositions or frameworks provide direction, reflect the theoretical perspective, and guide the search for relevant evidence.

There are different rationales for choosing a single case design (Yin 2014: 51). Purposeful sampling is conducted if an extreme case or an unusual case is chosen and if rarely observable phenomena can be investigated with regard to unknown matters and their relationships. Common cases allow conclusions for a broader class of cases. Revelatory cases provide the opportunity to investigate into a previously inaccessible inquiry, and the longitudinal study enables one to investigate a single case at several points in time. A rationale for multiple case designs has its strength in replication logic (Yin 2014: 56). In the case of literal replication, cases are selected to predict similar results. In the case of theoretical replication, cases are selected to predict contrasting results but for theoretical reasons. Yin provides several tactics to increase the reliability (protocol; data base) of the study.

Yin (2014: 103) emphasizes that interviews are one of the most important sources of data collection but considers other sources of qualitative data as well. Data 
triangulation is designed to narrow problems of construct validity, as multiple sources of data provide multiple measures of the same phenomenon. Yin (2014: 133) offers a number of data analysis strategies (e.g., case description; examining rival explanations) and analytic techniques which are apt to compare the proposed relationships with empirical patterns. Pattern-matching logic compares empirically based patterns with predicted patterns, enabling further data analysis techniques (explanation building, time series analysis, logic models, and cross-case synthesis). In analytical generalization, the theory is compared with the empirical results, leading to the modification or extension of the theory.

An appropriate model for this case study design can be identified in a paper by Ellonen et al. (2009). The paper is based on the emerging dynamic capability theory. The four cases were chosen for theoretical reasons to deliver an empirical contribution to the dynamic capability theory by investigating the relationship of dynamic capabilities and innovation outcomes. The authors followed a literal replication strategy and identified patterns between dynamic capabilities of the firms and their innovation outcomes.

Shane (2000) is an author who developed specific propositions from a framework and examined the propositions in eight entrepreneurial cases. Using several sources of interviews and archival data, the author compared the data with the propositions using the pattern-matching logic, which concluded in developing entrepreneurship theory.

\subsection{Case study research design 3: social construction of reality}

So far, the outlined case study research designs are based on positivist roots, but there is richness and variety in case study research stemming from different philosophical realms. The case study research design by Stake (1995, 2000, 2005), for example, is based on constructivist assumptions and aims to investigate the social construction of reality and meaning (Schwandt 1994: 125).

According to this philosophical assumption, there is no unique "real world" that preexists independently of human mental activity and symbolic language. The world is a product of socially and historically related interchanges amongst people (social construction). The access to reality is given through social constructions, such as language and shared meanings: "The meaning-making activities themselves are of central interest to social constructionists/constructivists, simply because it is the meaning-making/sense making attributional activities that shape action or (inaction)" (Guba and Lincoln 2005: 197). Therefore, the researcher is not looking for objective "facts", nor does he aim at identifying and measuring patterns which can be generalized. Contrarily, the constructivist is researching into specific actions, in specific places, at specific times. The scientist tries to understand the construction and the sharing of meaning (Schwandt 1994).

According to Stake (2005), the direction of the case study is shaped by the interest in the case. In an intrinsic case study, the case itself is of interest. The purpose is not theory-building but curiosity in the case itself. In an instrumental case study, the case itself is of secondary interest. It plays a supportive role, as it facilitates the understanding of a research issue. The case can be typical of other 
cases. Multiple or collective case study research designs extend the instrumental case study. It is assumed that a number of cases will increase the understanding and support theorizing by comparison of the cases.

The differentiation by Stake $(1995,2005)$ into intrinsic and instrumental cases guides the purposive sampling strategy. In intrinsic case studies, the case is, by definition, already selected. The researcher looks for specific characteristics, aiming for thick descriptions with the opportunity to learn. Representativeness or generalization is not considered. In instrumental case study design, purposive sampling leads to the phenomenon under investigation. In multiple case study designs, the ability to compare cases enhances the opportunity to theorize.

A case study requires an integrated, holistic comprehension of the case complexity. According to Stake (2005), the case study is constructed by qualitative data, such as observations, interviews, and documents. Triangulation first serves as clarification of meaning. Second, the researcher is interested in the diversity of perceptions.

Two methods of data analysis are considered in such qualitative case study design: direct interpretation and categorical aggregation (Stake 1995: 74). The primary task of an intrinsic case study is to understand the case. This interpretation is offered to the reader, but the researcher has to provide the material in a sufficient way (thick descriptions), so that the reader can learn from the case as well as draw his or her own conclusions. Readers can thus make some generalizations based on personal and vicarious experiences ("naturalistic generalization"). In instrumental case studies, the understanding of phenomena and relationships leads to categorical aggregation, and the focus is on how the phenomenon exists across several cases.

Greenwood and Suddaby (2006), for example, used the instrumental case study design by Stake, combining network location theory and dialectical theory. They identified new dynamics creating a process model of elite institutional entrepreneurship.

Ituma et al. (2011) highlighted the social construction of reality in their study of career success. The majority of career studies have been conducted in Western countries and findings have been acknowledged as universally applicable. The authors demonstrated that realities of managers in other areas are constructed differently. As a result of their study, they provided a contextually sensitive frame for the analysis of career outcomes.

\subsection{Case study research design 4: anomalies}

Identifying anomalies as a basis for further research is common in management and organization research (Gilbert and Christensen 2005). In case study research, the extended case study method is used for this case study research design (Ridder 2016). Following Burawoy (1991, 1998, 2009), the research question derives from curiosity. Researchers normally look at what is "interesting" and what is "surprising" in a social situation that existing theory cannot explain. Initially, it is not important whether the expectations develop from some popular belief, stereotype, or from an academic theory. The extended case study research design is guided by anomalies that the previous theory was not able to explain through 
internal contradictions of theory, theoretical gaps, or silences. An anomaly does not reject theory, but rather demonstrates that the theory is incomplete. Theory is aimed to be improved by "... turning anomalies into exemplars" (Burawoy 1991: 10).

The theoretical sampling strategy in this case study research design stems from the theoretical failure in confrontation with the site. According to the reflexive design, such cases do not favour individuals or isolated phenomena, but social situations in which a comparative strategy allows the tracing of differences across the cases to external forces.

In the extended case study, the researcher deals with qualitative data, but also considers the broader complex social situation. The researcher engages into a dialogue with the respondents (Burawoy (1991, 1998, 2009). An interview is an intervention into the life of a respondent. By means of mutual interaction it is possible to discover the social order under investigation. The observer has to unpack those situational experiences by means of participant observation and mutual interpretation. This situational comprehension aims at understanding divergent "voices", reflecting the variety of respondents' understandings of the social situation.

As in other sciences, these voices have to be aggregated. This aggregation of multiple readings of a single case is conducted by turning the aggregation into social processes: "The move from situation to process is accomplished differently in different reflexive methods, but it is always reliant on existing theory" (Burawoy 2009: 41). Social processes are now traced to the external field as the conditions of the social processes. Consequently, this leads to the question concerning "... how those micro situations are shaped by wider structures" (Burawoy 1991: 282). "Reflexive science insists, therefore, on studying the everyday world from the standpoint of its structuration, that is, by regarding it as simultaneously shaped by and shaping an external field of forces" (Burawoy 2009: 42). Such social fields cannot be held constant, which undermines the idea of replication. The external field is in continuous flux. Accordingly, social forces that influence the social processes are identified, shaping the phenomenon under investigation. Extension of theory does not target representativeness as a relationship of sample and population. Generality in reflexive science is to reconstruct an existing theory: "We begin with our favorite theory but seek not confirmations but refutations that inspire us to deepen that theory. Instead of discovering grounded theory, we elaborate existing theory. We do not worry about the uniqueness of our case, since we are not as interested in its representativeness as its contribution to reconstructing theory. Our theoretical point of departure can range from the folk theory of participants to any abstract law. We consider only that the scientist consider it worth developing" (Burawoy 2009: 43). Such elaboration stems from the identification of anomalies and offers new predictions with regard to the theory.

It is somewhat surprising that the extended case study design has been neglected in the management literature so far, and it appears that critical reflexive principles have to be resurrected as they have been in other disciplines (see the overview at Wadham and Warren 2014). Examples in the management and organization literature are rare. Danneels (2011) used the extended case study design to extend the dynamic capabilities theory. In his famous Smith Corona case, Danneels shows how a company tried to change its resource base. Based on detailed data, the Smith 
Corona case provides insights into the resource alteration processes and how dynamic capabilities operate. As a result, the paper fills a process gap in dynamic capability theory. Iterating between data collection and analysis, Danneels revealed resource cognition as an element not considered so far in dynamic capability theory. The use of the extended case study method is limited to the iteration of data and theory. First, there is "running exchange" (Burawoy 1991: 10) between field notes and analysis. Second, there is iteration between analysis and existing theory. Unlike Burawoy, who aims to reconstruct existing theory on the basis of "emergent anomalies" (Burawoy 1991: 11) considering social processes and external forces, Danneels confronts the dynamic capabilities literature with the Smith Corona case to extend the theory of dynamic capabilities.

\subsection{A comparison of case study research processes}

Commonalities and differences emerged from the comparison of the designs. Table 1 provides a brief summary of these main differences and the resulting portfolio of case study research designs which will be discussed in more detail.

There is an extensive range between the different designs regarding the research processes. In "no theory first", there is a broad and tentative research question with some preliminary variables at the outset. The research question may be modified during the study as well as the variables. This design avoids any propositions regarding relationships.

On the contrary, the research question in "gaps and holes" is strongly related to existing theory, focusing on "how and why" questions. The existing theory contains research gaps which, once identified within the existing theory, lead accordingly to assumed relationships which are the basis for framework and propositions to be matched by empirical data. This broad difference is even more elaborated by a design that aims the "social construction of reality". There is no research question at the outset, but a curiosity in the case or the case is a facilitator to understand a research issue. This is far away from curiosity in the "anomaly approach". Here, the research question is inspired by questioning why an anomaly cannot be explained by the existing theory. What kind of gaps, silences, or internal contradictions demonstrates the insufficiency of the existing theory?

Various sampling strategies are used across these case study research designs, including theoretical sampling and purposeful sampling, which serve different objectives. Theoretical sampling in "no theory first" aims at selecting a case or cases that are appropriate to highlight new or extend preliminary constructs and reveal new relationships. There is a distinct difference from theoretical sampling in the "anomalies" approach. Such a sampling strategy aims to choose a case that is a demonstration of the failure of the theory. In "gaps and holes" sampling is highly focused on the purpose of the case study. Extreme and unusual cases have other purposes compared to common cases or revelatory cases. A single case may be chosen to investigate deeply into new phenomena. A multiple case study may serve a replication logic by which the findings have relevance beyond the cases under investigation. In "social construction of reality", the sampling is purposeful as well, 
Table 1 Portfolio of case study research design: differences in underlying elements

\begin{tabular}{|c|c|c|c|c|}
\hline & \multicolumn{4}{|c|}{ Case study research designs } \\
\hline & No theory first & Gaps and holes & $\begin{array}{l}\text { Social } \\
\text { construction of } \\
\text { reality }\end{array}$ & Anomalies \\
\hline $\begin{array}{l}\text { Representative } \\
\text { scholars }\end{array}$ & Eisenhardt & Yin & Stake & Burawoy \\
\hline The case & $\begin{array}{l}\text { Research question; } \\
\text { A priori constructs, } \\
\text { variables; } \\
\text { No assumed } \\
\text { relationships }\end{array}$ & $\begin{array}{l}\text { Research question; } \\
\text { Existing theory; } \\
\text { Proposition; } \\
\text { Framework }\end{array}$ & $\begin{array}{l}\text { Curiosity in the } \\
\text { case; } \\
\text { Understanding of } \\
\text { research issues }\end{array}$ & $\begin{array}{l}\text { Curiosity; } \\
\text { Existing theory; } \\
\text { Anomalies; } \\
\text { Internal } \\
\text { contradictions; } \\
\text { Gaps, silences }\end{array}$ \\
\hline The data & $\begin{array}{l}\text { Theoretical } \\
\text { sampling; } \\
\text { Qualitative data as } \\
\text { the primary choice }\end{array}$ & $\begin{array}{l}\text { Purposeful } \\
\text { sampling; } \\
\text { Qualitative data as } \\
\text { the primary } \\
\text { choice }\end{array}$ & $\begin{array}{l}\text { Purposive } \\
\text { sampling; } \\
\text { Thick } \\
\text { descriptions; } \\
\text { Holistic } \\
\text { comprehension }\end{array}$ & $\begin{array}{l}\text { Theoretical } \\
\text { sampling; } \\
\text { Dialogue of } \\
\text { observer and } \\
\text { participants; } \\
\text { Participant } \\
\text { observation }\end{array}$ \\
\hline The analysis & $\begin{array}{l}\text { Emerging constructs } \\
\text { and relationships }\end{array}$ & $\begin{array}{l}\text { Pattern-matching as } \\
\text { a primary choice; } \\
\text { Analytic } \\
\text { generalization }\end{array}$ & $\begin{array}{l}\text { Learning from } \\
\text { the case; } \\
\text { Categorical } \\
\text { aggregation }\end{array}$ & $\begin{array}{l}\text { Social processes; } \\
\text { Structuration; } \\
\text { Reconstruction of } \\
\text { theory }\end{array}$ \\
\hline
\end{tabular}

but for different reasons. Either the case is of interest per se or the case represents a good opportunity to understand a theoretical issue.

Although qualitative data are preferred in all of the designs, quantitative data are seen as a possible opportunity to strengthen cases by such data. Nevertheless, in "social construction of reality", there is a strong emphasis on thick descriptions and a holistic understanding of the case. This is in contrast to a more construct- and variable- oriented collection of data in "no theory first" and "gaps and holes". In addition, in contrast to that, the "anomaly" approach is the only design that receives data from dialogue between observer and participants and participant observation.

Finally, data analysis lies within a wide range. In "no theory first", the research process is finalized by inspecting the emerging constructs within the case or across cases. Based on a priory constructs, systematic comparisons reveal patterns and relationships resulting in a tentative theory. On the contrary, in "gaps and holes", a tentative theory exists. The final analysis concentrates on the matching of the framework or propositions with patterns from the data. While both of these approaches condense data, the approach of "social construction of reality" ends the research process with thick descriptions of the case to learn from the case or with categorical comparisons. In the "anomaly" approach, the data analysis is aggregation of data, but these aggregated data are related to its external field and their pressures and influences by structuration to reconstruct the theory. 
As a result, it is unlikely that the specified case study designs contribute to theory in a homogeneous manner. This result will be discussed in light of the question regarding how these case study designs can inform theory at several points of a continuum of theory. This analysis will be outlined in the following sections. In a first step, I review the main elements of a theory continuum. In a second step, I discuss the respective contribution of the previously identified case study research designs to the theory continuum.

\section{Elements of a theory continuum}

What a theory is and what a theory is not is a classic debate (Sutton and Staw 1995; Weick 1995). Often, theories are described in terms of understanding relationships between phenomena which have not been or were not well understood before (Chiles 2003; Edmondson and McManus 2007; Shah and Corley 2006), but there is no overall acceptance as to what constitutes a theory. Theory can be seen as a final product or as a continuum, and there is an ongoing effort to define different stages of this continuum (Andersen and Kragh 2010; Colquitt and Zapata-Phelan 2007; Edmondson and McManus 2007; Snow 2004; Swedberg 2012). In the following section, basic elements of the theory and the construction of the theory continuum are outlined.

\subsection{Basic elements of a theory}

Most of the debate concerning what a theory is comprises three basic elements (Alvesson and Kärreman 2007; Bacharach 1989; Dubin 1978; Kaplan 1998; Suddaby 2010; Weick 1989, 1995; Whetten 1989). A theory comprises components (concepts and constructs), used to identify the necessary elements of the phenomenon under investigation. The second is relationships between components (concepts and constructs), explaining the how and whys underlying the relationship. Third, temporal and contextual boundaries limit the generalizability of the theory. As a result, definitions of theory emphasize these components, relationships, and boundaries:

"It is a collection of assertions, both verbal and symbolic, that identifies what variables are important for what reasons, specifies how they are interrelated and why, and identifies the conditions under which they should be related or not related" (Campbell 1990: 65).

“... a system of constructs and variables in which the constructs are related to each other by propositions and the variables are related to each other by hypotheses" (Bacharach 1989: 498).

"Theory is about the connections among phenomena, a story about why acts, events, structure, and thoughts occur. Theory emphasizes the nature of causal relationships, identifying what comes first as well as the timing of such events" (Sutton and Staw 1995: 378). 
“... theory is a statement of concepts and their interrelationships that shows

how and/or why a phenomenon occurs" (Corley and Gioia 2011: 12).

The terms "constructs" and "concepts" are either used interchangeably or with different meanings. Positivists use "constructs" as a lens for the observation of a phenomenon (Suddaby 2010). Such constructs have to be operationalized and measured. Non-positivists often use the term "concept" as a more value neutral term in place of the term construct (Gioia et al. 2013; Suddaby 2010: 354). Nonpositivists aim at developing concepts on the basis of data that contain richness and complexity of the observed phenomenon instead of narrow definitions and operationalizations of constructs. Gioia et al. (2013: 16) clarify the demarcation line between constructs and concepts as follows: "By 'concept,' we mean a more general, less well-specified notion capturing qualities that describe or explain a phenomenon of theoretical interest. Put simply, in our way of thinking, concepts are precursors to constructs in making sense of organizational worlds-whether as practitioners living in those worlds, researchers trying to investigate them, or theorists working to model them".

In sum, theories are a systematic combination of components and their relationships within boundaries. The use of the terms constructs and concepts is related to different philosophical assumptions reflected in different types of case study designs.

\subsection{Theory continuum}

Weick (1995) makes an important point that theory is more a continuum than a product. In his view, theorizing is a process containing assumptions, accepted principles, and rules of procedures to explain or predict the behavior of a specified set of phenomena. In similar vein, Gilbert and Christensen (2005) demonstrate the process character of theory. In their view, a first step of theory building is a careful description of the phenomena. Having already observed and described the phenomena, researchers then classify the phenomena into similar categories. In this phase a framework defines categories and relationships amongst phenomena. In the third phase, researchers build theories to understand (causal) relationships, and in this phase, a model or theory asserts what factors drive the phenomena and under what circumstances. The categorization scheme enables the researchers to predict what they will observe. The "test" offers a confirmation under which circumstances the theory is useful. The early drafts of a theory may be vague in terms of the number and adequateness of factors and their relationships. At the end of the continuum, there may be more precise variables and predicted relationships. These theories have to be extended by boundaries considering time and space.

Across that continuum, different research strategies have various strengths. Several classifications in the literature intend to match research strategies to the different phases of a theory continuum (Andersen and Kragh 2010; Colquitt and Zapata-Phelan 2007; Edmondson and McManus 2007; Snow 2004; Swedberg 2012). These classifications, although there are differences in terms, comprise three phases with distinguishable characteristics. 


\subsubsection{Building theory}

Here, the careful description of the phenomena is the starting point of theorizing. For example, Snow (2004) puts this phase as theory discovery, where analytic understandings are generated by means of detailed examination of data. Edmondson and McManus (2007) state the starting phase of a theory as nascent theory providing answers to new questions revealing new connections among phenomena. Therefore, research questions are open and researchers avoid hypotheses predicting relationships between variables. Swedberg (2012) highlights the necessity of observation and extensive involvement with the phenomenon at the early stage of theorybuilding. It is an attempt to understand something of interest by observing and interpreting social facts. Creativity and inspiration are necessary conditions to put observations into concepts and outline a tentative theory.

\subsubsection{Developing theory}

This tentative theory exists in the second phase of the continuum and has to be developed. Several possibilities exist. In theory extension, the preexisting constructs are extended to other groups or other contexts. In theoretical refinement, a modification of existing theoretical perspectives is conducted (Edmondson and McManus (2007). New antecedents, moderators, mediators, and outcomes are investigated, enhancing the explanation power of the tentative theory.

\subsubsection{Test of theories}

Constructs and relationships are well developed to a mature state; measures are precise and operationalized. Such theories are empirically tested with elaborate methods, and research questions are more precise. In the quantitative realm, testing of hypotheses is conducted and statistical analysis is the usual methodological foundation. Recently, researchers criticize that testing theories has become the major focus of scientists today (Delbridge and Fiss 2013); testing theories does not only happen to mature theory but to intermediate theory as well. The boundary between theory development and theory testing is not always so clear. While theory development is adding new components to a theory and elaborating the measures, testing a theory implies precise measures, variables, and predicted relationships considering time and space (Gilbert and Christensen (2005). It will be of interest whether case studies are eligible to test theories as well.

To summarize: there is a conversation as to where on a continuum of theory development, various methods are required to target different contributions to theory (methodological fit). In this discussion, case study research designs have been discussed as a homogeneous set that mostly contributes to theory-building in an exploratory manner. Hence, what is missing is a more differentiated analysis of how case study methodology fits into this conversation, particularly how case study research methodologically fits theory development and theory testing beyond its widely assumed explorative role. In the following section, the above types of case 
study research designs will be discussed with regard to their positions across the theory continuum.

This distinction adds to existing literature by demonstrating that case study research does not only contribute to theory-building, but also to the development of tentative theories and to the testing of theories. This distinction leads to the next question: is there any interplay between case study research designs and their contributions to the theory continuum? This paper aims at reconciling this interplay with regard to case study design by mirroring phases of a theory continuum with specific types of case study research designs as outlined above. The importance of the interplay between theory and method lies in the capacity to generate and shape theory, while theory can generate and shape method. "In this long march, theory and method surely matter, for they are the tools with which we build both our representations and understandings of organizational life and our reputations" (van Maanen et al. 2007: 1145). Theory is not the same as methods, but a relationship of this interplay can broaden or restrict both parts of the equation (Swedberg 2012: 7).

In the following, I discuss how the above-delineated case study research designs unfold their capacities and contribute differently to the theory continuum to build, develop, and test theory.

\section{Discussion of the contribution of case study research to a theory continuum}

Case study research is diverse with distinct contributions to the continuum of theory. The following table provides the main differences in terms of contributions to theory and specifically locates the case study research designs on the theory continuum (Table 2).

In the following, I outline how these specific contributions of case study designs provide better opportunities to enhance the rigor of building theory, developing theory, testing, and reconstructing theory.

\subsection{Building theory}

In building theory, the phenomenon is new or not understood so far. There is no theory which explains the phenomenon. At the very beginning of the theory continuum, there is curiosity in the phenomenon itself. I focus on the intrinsic case study design which is located in the social construction of reality approach on the very early phase of the theory continuum, as intrinsic case study research design is not theory-building per se but curiosity in the case itself. It is not the purpose of the intrinsic case study to identify abstract concepts and relationships; the specific research strategy lies in the observation and description of a case and the primary method is observation, enabling understanding from personal and vicarious experience. This meets long lasting complaints concerning the lack of (new) theory in management and organization research and signals that the gap between research and management practice is growing. It is argued that the complexity of the reality is not adequately captured (Suddaby et al. 2011). It is claimed that management and 


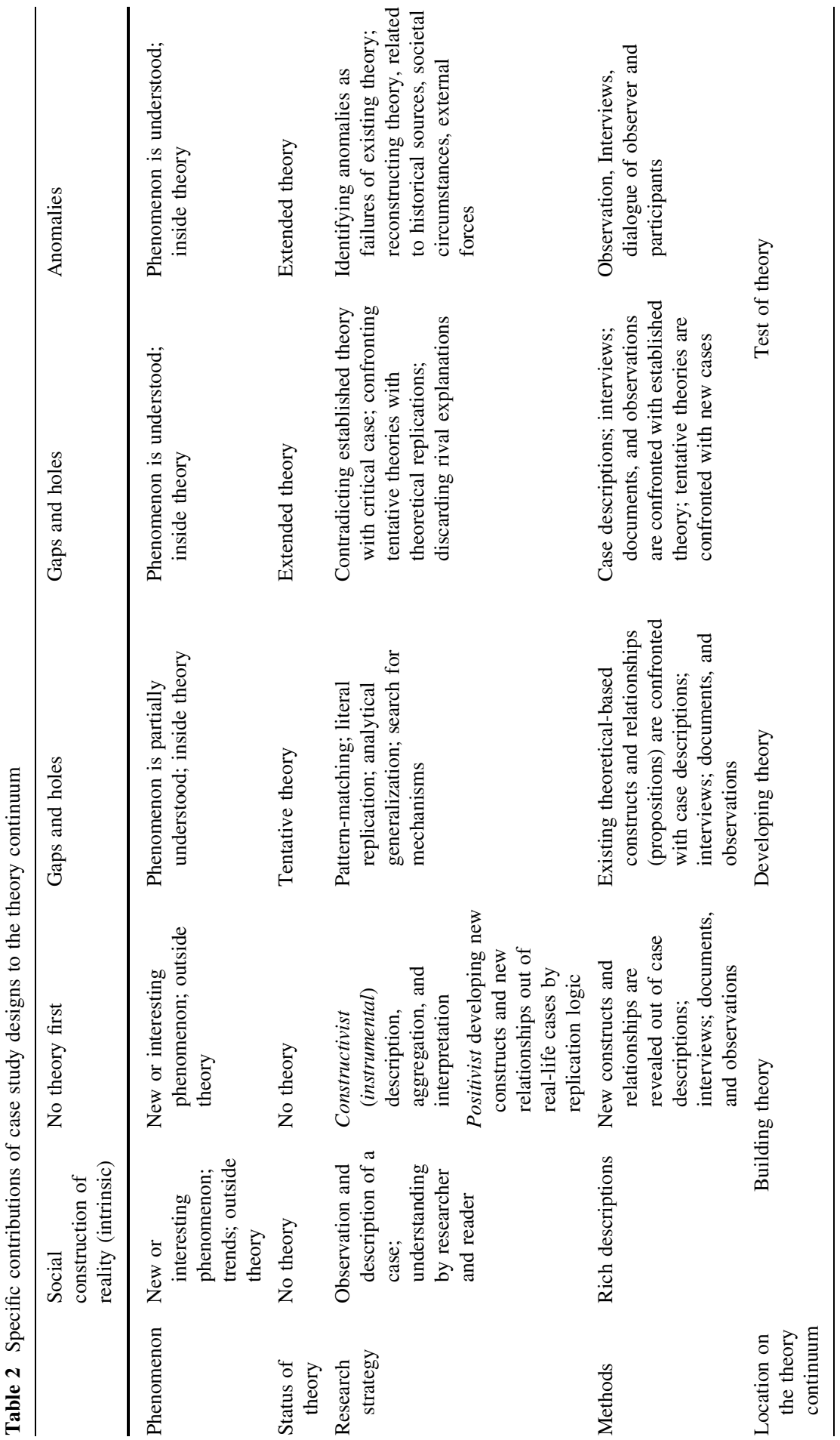


organization research systematically neglect the dialogue with practice and, as a result, miss new trends or recognize important trends with delay (Corley and Gioia 2011).

The specific case study research design's contribution to theory is in building concrete, context-dependent knowledge with regard to the identification of new phenomena and trends. Openness with regard to the new phenomena, avoiding theoretical preconceptions but building insights out of data, enables the elaboration of meanings and the construction of realities in intrinsic case studies. Intrinsic case studies will enhance the understanding by researcher and reader concerning new phenomena.

The "No Theory First" case study research design is a classic and often cited candidate for building theory. As the phenomenon is new and in the absence of a theory, qualitative data are inspected for aggregation and interpretation. In instrumental case study design, a number of cases will increase the understanding and support building theories by description, aggregation, and interpretation (Stake 2000). New themes and concepts are revealed by case descriptions, interviews, documents, and observations, and the analysis of the data enables the specific contribution of the case study design through a constructivist perspective in theorybuilding.

Although the design by Eisenhardt (1989) stems from other philosophical assumptions and there are variations and developments in this design, there is still an overwhelming tendency to quote and to stick to her research strategy which aims developing new constructs and new relationships out of real-life cases. Data are collected mainly by interviews, documents, and observations. From within-site analysis and cross-case analysis, themes, concepts, and relationships emerge. Shaping hypotheses comprises: “... refining the definition of the construct and (...) building evidence which measures the construct in each case" (Eisenhardt 1989: 541). Having identified the emerged constructs, the emergent relationships between constructs are verified in each case. The underlying logic is validation by replication. Cases are treated as experiments in which the hypotheses are replicated case by case. In replication logic cases that confirm the emergent relationships enhance confidence in the validity of the relationships. Disconfirmation of the relationships leads to refinement of the theory. This is similar to Yin's replication logic, but targets the precision and measurement of constructs and the emerging relationships with regard to the emerging theory. The building of a theory concludes in an understanding of the dynamics underlying the relationship; the primary theoretical reasons for why the relationships exist (Huy 2012). Finally, a visual theory with "boxes and arrows" (Eisenhardt and Graebner 2007) may visually demonstrate the emerged theory. The theory-building process is finalized by iterating case data, emerging theory, and extant literature.

The "No Theory First" and "Social Construction of Reality" case study research designs, although they represent different philosophical assumptions, adequately fit the theory-building phase concerning new phenomena. The main contribution of case study designs in this phase of the theory continuum lies in the generation of tentative theories. 
Case studies at this point of the theory continuum, therefore, have to demonstrate: why the phenomenon is new or of interest; that no previous theory that explains the phenomenon exists; how and why detailed descriptions enhance the understanding of the phenomenon; and how and why new concepts (constructs) and new relationships will enhance our understanding of the phenomenon.

As a result, it has to be demonstrated that the research strategy is in sync with an investigation of a new phenomenon, building a tentative theory.

\subsection{Developing theory}

In the "Gaps and Holes" case study research design, the phenomenon is partially understood. There is a tentative theory and the research strategy is theory driven. Compared to the theory-building phase, the existence and not the development of propositions differentiate this design along the continuum. The prediction comes first, out of an existing theory. The research strategy and the data have to be confronted by pattern-matching. Pattern-matching is a means to compare the theoretically based predictions with the data in the site: "For case study analysis, one of the most preferred techniques is to use a pattern-matching logic. Such a logic (...) compares an empirically based pattern-that is, one based on the findings from your case study-with a predicted one made before you collected your data (....)" (Yin 2014: 143). The comparison of propositions and the rich case material is the ground for new elements or relationships within the tentative theory.

Such findings aim to enhance the scientific usefulness of the theory (Corley and Gioia 2011). To enhance the validity of the new elements or relationships of the tentative theory, literal replication is a means to confirm the new findings. By that, the theory is developed by new antecedents, moderators, mediators, or outcomes. This modification or extension of the theory contributes to the analytical generalization of the theory.

If new cases provide similar results, the search for regularities is based on more solid ground. Therefore, the strength of case study research in "Gaps and Holes" lies in search for mechanisms in their specific context which can reveal causes and effects more precisely.

The "Gaps and Holes" case study research design is an adequate candidate for this phase of the theory continuum. Case studies at this point of the theory continuum, therefore, have to outline the tentative theory; to demonstrate the lacks and gaps of the tentative theory; to specify how and why the tentative theory is aimed to be extended and/or modified; to develop theoretically based propositions which guide the investigation; and to evaluate new elements, relationships, and mechanisms related to the previous theory (analytical generalization).

As a result and compared to theory-building, a different research strategy exists. While in theory building the research strategy is based on the eliciting of concepts (constructs) and relationships out of data, in theory development, it has to be demonstrated that the research strategy aims to identify new elements and relationships within a tentative theory, identifying mechanisms which explain the phenomenon more precisely. 


\subsection{Test of theory}

In "Gaps and Holes" and "Anomalies", an extended theory exists. The phenomenon is understood. There is no search for additional components or relationships. Mechanisms seem to explain the functioning or processes of the phenomenon. The research strategy is focused on testing whether the theory holds under different circumstances or under different conditions. Such a test of theories is mainly the domain of experimental and quantitative studies. It is based on previously developed constructs and variables which are the foundation for stating specific testable hypotheses and testing the relations on the basis of quantitative data sets. As a result, highly sophisticated statistical tools enable falsification of the theory. Therefore, testing theory in "Gaps and Holes" is restricted on specific events.

Single case can serve as a test. There is a debate in case study research whether the test of theories is related to the falsification logic of Karl Popper (Flyvbjerg 2006; Tsang 2013). Another stream of the debate is related to theoretical generalizability (Hillebrand et al. 2001; Welch et al. 2011). More specifically, test in" Gaps and Holes" is analogous to a single experiment if a single case represents a critical case. If the theory has specified a clear set of propositions and defines the exact conditions within which the theory might explain the phenomena under investigation, a single case study, testing the theory, can confirm or challenge the theory. In sum Yin states: "Overall, the single-case design is eminently justifiable under certain conditions-where the case represents (a) a critical test of existing theory, ..." (Yin 2014: 56). In their survey in the field of International Business, Welch et al. conclude: "In addition, the widespread assumption that the role of the case study lies only in the exploratory, theory-building phase of research downplays its potential to propose causal mechanisms and linkages, and test existing theories" (Welch et al. 2011: 755).

In multiple case studies, a theoretical replication is a test of theory by comparing the findings with new cases. If a series of cases have revealed pattern-matching between propositions and the data, theoretical replication can be revealed by new waves of cases with contrasting propositions. If the contrasting propositions reveal contrasting results, the findings of the first wave are confirmed. Several possibilities exist to test the initial findings of multiple case studies using different lenses from inside and outside the management realm (Corley and Gioia 2011; LePine and Wilcox-King 2010; Okhuysen and Bonardi 2011; Zahra and Newey 2009), but have not become a standard in case study research.

In rival explanations, rival theoretical propositions are developed as a test of the previous theory. This can be distinguished from theoretical replication where contrasting propositions aim to confirm the initial findings. This can, as well, be distinguished from developing theory where rival explanations might develop theory by the elimination of possible influences (interventions, implementations). The rich data enable one to identify internal and external interventions that might be responsible for the findings. Alternative explanations in a new series of cases enable to test, whether a theory "different from the original theory explains the results better (...)" (Yin 2014: 141). 
As a result, it astonishes that theoretical replication and rival explanations, being one of the strengths of case study research, are rarely used. Although the general debate about "lenses" has informed the discussion about theory contributions, this paper demonstrates that there is a wide range of possible integration of vertical or horizontal lenses in case study research design. Case study research designs aiming to test theories have to outline modes of replication and the elimination of rival explanations.

The "anomaly approach" is placed in the final phase of the theory testing, as well. In this approach, a theory exists, but the theory fails to explain anomalies. Burawoy goes a step further. While Yin (2014) sees a critical case as a test that challenges or contradicts a well formulated theory, in Burawoy's approach, in contrast to falsification logic (Popper 2002), the theory is not rejected but reconstructed. Burawoy relates extended case study design to society and history. Existing theory is challenged by intervention into the social field. Identifying processes of historical roots and social circumstances and considering external forces by structuration lead to the reconstruction of the theory.

It is surprising that this design has been neglected so far in management research. Is there no need to reflect social tensions and distortions in management research? While case study research has, per definition, to investigate phenomena in its natural environment, it is hard to understand why this design has widely been ignored in management and organization research. As a result, testing theory in case study research has to demonstrate that an extended theory exists; a critical case or an anomaly can challenge the theory; theoretical replication and rival explanations will be means to contradict or confirm the theory; and societal circumstances and external forces explain the anomaly.

Compared to theory-building (new concepts/constructs and relationships out of data) and theory development (new elements and relationships within a tentative theory), testing theory challenges extended theory by empirical investigations into failures and anomalies that the current theory cannot explain.

\section{Conclusion}

Case studies provide a better understanding of phenomena regarding concrete context-dependent knowledge (Andersen and Kragh 2010; Flyvbjerg 2006: 224), but as literature reviews indicate, there is still confusion regarding the adequate utilization of case study methodology (Welch et al. 2011). This can be interpreted in a way that authors and even reviewers are not always aware of the methodological fit in case study research. Case study research is mainly narrowed to its "explorative" function, neglecting the scope of possibilities that case study research provides. The claim for more homogeneity of specified rules in case study research misses the important aspect that a method is not a means in itself, but aims at providing improved theories (van Maanen et al. 2007). This paper contributes to the fit of case study research designs and the theory continuum regarding the following issues. 


\subsection{Heterogeneity of case study designs}

Although case study research, overall, has similar characteristics, it incorporates various case study research designs that have heterogeneous theoretical goals and use various elements to reach these goals. The analysis revealed that the classical understanding, whereby case study research is adequate for the "exploration" of a theory and quantitative research is adequate for "testing" theory, is oversimplified. Therefore, the theoretical goals of case study research have to be outlined precisely. This study demonstrates that there is variety of case study research designs that have thus far been largely neglected. Case study researchers can utilize the entire spectrum, but have to consider how the phenomenon is related to the theory continuum.

Case study researchers have to demonstrate how they describe new or surprising phenomena, develop new constructs and relationships, add constructs (variables), antecedents, outcomes, moderators, or mediators to a tentative theory, challenge a theory by a critical case, theoretical replication or discarding rival explanations, and reconstruct a theory by tracking failures and anomalies to external circumstances.

\subsection{Methodological fit}

The rigor of the case study can be enhanced by considering the specific contribution of various case study research designs in each phase of the theory continuum. This paper provides a portfolio of case study research designs that enables researchers and reviewers to evaluate whether the case study arsenal has been adequately located:

At an early phase of the theory continuum, case studies have their strengths in rich descriptions and investigations into new or surprising empirical phenomena and trends. Researchers and readers can benefit from such rich descriptions in understanding and analyzing these phenomena.

Next, on the theory continuum, there is the well-known contribution of case study research in building tentative theory by eliciting constructs or concepts and their relationships out of data.

Third, development of theories is strongly related to literal replication. Strict comparisons, on the one hand, and controlled theoretical advancement, on the other hand, enable the identification of mechanisms, strengthen the notions of causality, and provide generalizable statements.

Fourth, there are specific circumstances under which case study approaches enable one to test theories. This is to confront the theory with a critical case, to test findings of pattern-matching by theoretical replication and discarding rival explanations. Therefore, "Gaps and Holes" provide the opportunity for developing and testing theories through case study design on the theory continuum.

Finally, testing and contradicting theory are not the final rejection of a theory, but is the basis for reconstructing theory by means of case study design. Anomalies can be traced to historical sources, social processes, and external forces.

This paper demonstrates that the precise interplay of case study research designs and theory contributions on the theory continuum is a prerequisite for the 
contribution of case study research to better theories. If case study research design is differentiated from qualitative research, the intended contribution to theory is stated and designs that fit the aimed contribution to theory are outlined and substantiated; this will critically enhance the rigor of case study research.

Open Access This article is distributed under the terms of the Creative Commons Attribution 4.0 International License (http://creativecommons.org/licenses/by/4.0/), which permits unrestricted use, distribution, and reproduction in any medium, provided you give appropriate credit to the original author(s) and the source, provide a link to the Creative Commons license, and indicate if changes were made.

\section{References}

Alvesson, M., and D. Kärreman. 2007. Constructing mystery: Empirical matters in theory development. Academy of Management Review 32: 1265-1281.

Andersen, P.H., and H. Kragh. 2010. Sense and sensibility: two approaches for using existing theory in theory-building qualitative research. Industrial Marketing Management 39: 49-55.

Bacharach, S.B. 1989. Organizational theories: some criteria for evaluation. Academy of Management Review 14: 496-515.

Baxter, P., and S. Jack. 2008. Qualitative case study methodology: study design and implementation for novice researchers. The Qualitative Report 13: 544-559.

Bingham, C.B., and K.M. Eisenhardt. 2011. Rational heuristics: the 'simple rules' that strategists learn from process experience. Strategic Management Journal 32: 1437-1464.

Burawoy, M. 1991. Ethnography unbound. Power and resistance in the modern metropolis: University of California Press.

Burawoy, M. 1998. The extended case method. Sociological Theory 16: 4-33.

Burawoy, M. 2009. The extended case method. Four countries, four decades, four great transformations, and one theoretical tradition. Berkeley: University of California Press.

Burns, R.B. 2000. Introduction to research methods. United States of America: SAGE publications.

Campbell, J.P. 1990. The role of theory in industrial and organizational psychology. In Handbook of industrial and organizational psychology, 2nd ed, ed. M.D. Dunnette, L.M. Hough, and H.C. Triandis, 39-73. Palo Alto: Consulting Psychologists Press.

Chiles, T.H. 2003. Process theorizing: too important to ignore in a kaleidic world. Academy of Management Learning \& Education 2: 288-291.

Colquitt, J.A., and C.P. Zapata-Phelan. 2007. Trends in theory building and theory testing: a five-decade study of the Academy of Management Journal. Academy of Management Journal 50: 1281-1303.

Corbin, J.M., \& Strauss, A.L. 2015. Basics of qualitative research: Techniques and procedures for developing grounded theory (4th ed). Los Angeles, CA: Sage Publications.

Corley, K.G., and D.A. Gioia. 2011. Building theory about theory building: what constitutes a theoretical contribution? Academy of Management Review 36: 12-32.

Danneels, E. 2011. Trying to become a different type of company: dynamic capability at Smith Corona. Strategic Management Journal 32: 1-31.

Davis, J.P., and K.M. Eisenhardt. 2011. Rotating leadership and collaborative innovation: recombination processes in symbiotic relationships. Administrative Science Quarterly 56: 159-201.

Delbridge, R., and P.C. Fiss. 2013. Editors' comments: styles of theorizing and the social organization of knowledge. Academy of Management Review 38: 325-331.

Dooley, L.M. 2002. Case study research and theory building. Advances in Developing Human Resources 4: 335-354.

Dubin, R. 1978. Theory building. New York: Free Press.

Dyer, W.G., and A.L. Wilkins. 1991. Better stories, not better constructs, to generate better theory: a rejoinder to Eisenhardt. Academy of Management Review 16: 613-619.

Edmondson, A.C., and S.E. McManus. 2007. Methodological fit in management field research. Academy of Management Review 32: 1155-1179.

Eisenhardt, K.M. 1989. Building theories from case study research. Academy of Management Review 14: $532-550$. 
Eisenhardt, K.M. 1991. Better stories and better constructs: The case for rigor and comparative logic. Academy of Management Review, 16(3): 620-627.

Eisenhardt, K.M., and M.E. Graebner. 2007. Theory building from cases: opportunities and challenges. Academy of Management Journal 50: 25-32.

Ellonen, H.K., P. Wikström, and A. Jantunen. 2009. Linking dynamic-capability portfolios and innovation outcomes. Technovation 29: 753-762.

Fiss, P.C. 2009. Case studies and the configurational analysis of organizational phenomena. In The SAGE handbook of case-based methods, ed. D.S. Byrne, and C.C. Ragin, 424-440. London/Thousand Oaks: SAGE.

Flick, U. 2009. An introduction to qualitative research, 4th ed. London: SAGE.

Flyvbjerg, B. (2006). Five misunderstandings about case-study research. Qualitative Inquiry, 12(2): 219-245.

Gilbert, C.G., and C.M. Christensen. 2005. Anomaly-seeking research: thirty years of development in resource allocation theory. In From resource allocation to strategy, ed. J.L. Bower, and C.G. Gilbert, 71-89. Oxford: University Press, Oxford.

Gioia, D.A., K.G. Corley, and A.L. Hamilton. 2013. Seeking qualitative rigor in inductive research: notes on the Gioia methodology. Organizational Research Methods 16: 15-31.

Gomm, R., M. Hammersley, and P. Foster. 2000. Case study method. Key issues, key texts. London/ Thousand Oaks: Sage Publications.

Greenwood, R., and R. Suddaby. 2006. Institutional entrepreneurship in mature fields: the big five accounting firms. Academy of Management Journal 49: 27-48.

Guba, E.G., and Y.S. Lincoln. 2005. Paradigmatic controversies, contradictions, and emerging confluences. In The SAGE handbook of qualitative research, 3rd ed, ed. N.K. Denzin, and Y.S. Lincoln, 191-215. London, Thousand Oaks: Sage Publications.

Hillebrand, B., R.A.W. Kok, and W.G. Biemans. 2001. Theory-testing using case studies: a comment on Johnston, Leach, and Liu. Industrial Marketing Management 30: 651-657.

Huy, Q.N. 2012. Improving the odds of publishing inductive qualitative research in Premier Academic Journals. The Journal of Applied Behavioral Science 48: 282-287.

Ituma, A., R. Simpson, F. Ovadje, N. Cornelius, and C. Mordi. 2011. Four 'domains' of career success: how managers in Nigeria evaluate career outcomes. The International Journal of Human Resource Management 22: 3638-3660.

Kaplan, A. 1998. The conduct of inquiry. Methodology for behavioral science. New Brunswick, N.J.: Transaction Publishers.

Lee, T.W. 1999. Using qualitative methods in organizational research. Organizational research methods series. Thousand Oaks: Sage Publications.

LePine, J.A., and A. Wilcox-King. 2010. Editorśs comments: developing novel theoretical insight from reviews of existing rheory and research. Academy of Management Review 35: 506-509.

Mason, J. 2002. Qualitative researching, 2nd ed. London, Thousand Oaks: Sage Publications.

Miles, M.B., Huberman, M.A., \& Saldana, J. 2014. Qualitative data analysis: A methods sourcebook (3rd ed). Los Angeles, CA: Sage Publications.

Okhuysen, G., and J.P. Bonardi. 2011. The challenges of building theory by combining lenses. Academy of Management Review 36: 6-11.

Piekkari, R., C. Welch, and E. Paavilainen. 2009. The case study as disciplinary convention: evidence from international business journals. Organizational Research Methods 12: 567-589.

Popper, K.R. 2002. Logik der Forschung. Tübingen: Mohr Siebeck.

Ravenswood, K. 2011. Eisenhardt's impact on theory in case study research. Journal of Business Research 64: 680-686.

Ridder, H.G. 2016. Case study research. Approaches, methods, contribution to theory. Sozialwissenschaftliche Forschungsmethoden, vol. 12. München/Mering: Rainer Hampp Verlag.

Schwandt, T.A. 1994. Constructivist, interpretivist approaches to human inquiry. In Handbook of qualitative research, ed. N.K. Denzin, and Y.S. Lincoln, 118-137. Thousand Oaks: Sage Publications.

Shah, S.K., and K.G. Corley. 2006. Building better theory by bridging the quantitative-qualitative divide. Journal of Management Studies 43: 1821-1835.

Shane, S. 2000. Prior knowledge and the discovery of entrepreneurial opportunities. Organization Science 11: 448-469. 
Snow, C.C. 2004. Thoughts on alternative pathways to theoretical development: Theory generation, extension, and refinement. In Workshop on scientific foundations of qualitative research, ed. C.C. Ragin, J. Nagel, and P. White, 133-136. Arlington, VA: National Science Foundation.

Stake, R.E. 1995. The art of case study research. London, Thousand Oaks: Sage Publications.

Stake, R.E. 2000. The case study and generalizability. In Case study method. Key issues, key texts, ed. R. Gomm, M. Hammersley, and P. Foster, 19-26. London/Thousand Oaks: Sage Publications.

Stake, R.E. 2005. Qualitative case studies. In The SAGE handbook of qualitative research, 3rd ed, ed. N.K. Denzin, and Y.S. Lincoln, 443-466. London, Thousand Oaks: Sage Publications.

Suddaby, R. 2010. Editor's comments: construct clarity in theories of management and organization. Academy of Management Review 35: 346-357.

Suddaby, R., C. Hardy, and Q.N. Huy. 2011. Introduction to special topic forum: where are the new theories of organization? Academy of Management Review 36: 236-246.

Sutton, R.I., and B.M. Staw. 1995. What theory is not. Administrative Science Quarterly 40: 371-384.

Swedberg, R. 2012. Theorizing in sociology and social science: turning to the context of discovery. Theory and Society 41: 1-40.

Tsang, E.W.K. 2013. Generalizing from research findings: the merits of case studies. International Journal of Management Reviews 16: 369-383.

van Maanen, J., J.B. Sørensen, and T.R. Mitchell. 2007. The interplay between theory and method. Academy of Management Review 32: 1145-1154.

Vaughan, D. 1992. Theory elaboration: The heuristics of case analysis. In What is a case?, ed. C.C. Ragin, and H.S. Becker, 173-202. Exploring the foundations of social inquiry: Cambridge University Press, Cambridge, New York.

Wadham, H., and R.C. Warren. 2014. Telling organizational tales the extended case method in practice. Organizational Research Methods 17: 5-22.

Weick, K.E. 1989. Theory construction as disciplined imagination. Academy of Management Review 14: 516-531.

Weick, K.E. 1995. What theory is not, theorizing is. Administrative Science Quarterly 40: 385-390.

Welch, C., R. Piekkari, E. Plakoyiannaki, and E. Paavilainen-Mäntymäki. 2011. Theorising from case studies: towards a pluralist future for international business research. Journal of International Business Studies 42: 740-762.

Whetten, D.A. 1989. What constitutes a theoretical contribution? Academy of Management Review 14: 490-495.

Yin, R.K. 2014. Case study research. Design and methods, 5th ed. London, Thousand Oaks: Sage Publications.

Zahra, S.A., and L.R. Newey. 2009. Maximizing the Impact of Organization Science: theory-Building at the Intersection of Disciplines and/or Fields. Journal of Management Studies 46: 1059-1075. 